\title{
Breast tuberculosis: a diagnosis not to be forgotten
}

\author{
(D) Fatma Hammami1,2, (D) Makram Koubaa1,2, (D) Yosr Hentati ${ }^{3}$, (D) Amal Chakroun 1,2 , (D) Khaoula Rekik ${ }^{1,2}$, \\ (D) Chakib Marrakchi1,2, (D) Zeineb Mnif ${ }^{3}$, (D) Fatma Smaoui1,2, (D) Mounir Ben Jemaa1,2 \\ ${ }^{1}$ Department of Infectious Diseases, University of Sfax, Hedi Chaker University Hospital, Sfax, Tunisia \\ 2Extra-pulmonary Research Unity UR17SP12, Hedi Chaker University Hospital, Sfax, Tunisia \\ 3Department of Radiology, University of Sfax, Hedi Chaker University Hospital, Sfax, Tunisia
}

\section{Abstract}

Objective: To study the clinical characteristics and imaging features of breast tuberculosis (TB) and to describe treatment.

Material and Methods: A retrospective study including all patients hospitalized in the infectious diseases department for breast TB between 1997 and 2018.

Results: Twenty-two women, with a mean age of $39 \pm 12$ years, were identified. In total, 18 patients were multiparous (81.8\%). Both lump and mastalgia were the presenting symptoms in 19 cases (86.3\%). Ipsilateral axillary lymphadenopathy was noted in 14 cases (63.6\%). The most common finding on ultrasound was a well or poorly defined mass lesion, noted in 17 cases (77.2\%), followed by fistulous tracts in seven cases (31.8\%). Mammography showed focal, asymmetric breast density in 17 cases (89.5\%) and diffuse in two cases (10.5\%). The diagnosis was confirmed based on the presence of epithelioid cell granulomas and caseous necrosis in 13 cases (59.1\%). Patients received antitubercular therapy for a mean duration of $11 \pm 5$ months. The disease evolution was favorable in 20 cases (91\%). There were two relapsing cases (9\%).

Conclusion: Breast TB should be considered in the differential diagnosis of young patients presenting with palpable lump with axillary lymphadenopathy, especially in endemic regions. The diagnosis confirmation usually requires an excision biopsy providing histological or bacteriological evidence. (J Turk Ger Gynecol Assoc 2021; 22: 107-11)

Keywords: Breast, tuberculosis, ultrasonography, mammography, lymphadenopathy

Received: 14 November, 2020 Accepted: 29 January, 2021

\section{Introduction}

Tuberculosis (TB) remains a public health issue, with an estimated 10 million new cases annually, worldwide (1). It is a multisystem disease that might involve any organ system. Breast TB is a rare disease, even in developing countries (2). Its incidence reaches $4 \%$ of all breast lesions in endemic regions (3). Patients usually consult for an isolated lump, and usually without constitutional symptoms of TB, which are present in around $20 \%$ of the cases (4). The diagnosis is often delayed due to the low index of suspicion and similarities with other breast pathologies. Breast TB is often mistaken for pyogenic abscesses or breast cancer (5). Imaging findings are often helpful in order to guide clinicians. However, breast TB has no specific ultrasonographic findings, which might present as a heterogeneous, hypoechoic, irregularly bordered mass with internal echoes or thick-walled cystic lesions (6).

Although Tunisia is a country with an intermediate rate of endemic TB (7), breast TB remains a very rare disease, representing $0.2 \%$ of extrapulmonary $\mathrm{TB}$ cases (8). In this context, the aim of this work was to study the clinical characteristics and imaging features of breast TB and to describe treatment.

\section{Material and Methods}

\section{Study design}

A retrospective study was conducted including all patients hospitalized in the infectious diseases department for breast TB over a 22-year period, between 1997 and 2018. 


\section{Data collection and case definitions}

Data was collected from the patients' medical records. The age, gender, place of residence (urban/rural) and previous medical history of patients were recorded. Clinical symptoms, laboratory investigations, microbiological and histopathological results, and imaging features were reviewed. The treatment received, its duration and the disease evolution were also collected.

Patients included in the study had microbiologically or histopathologically confirmed breast TB. By default, patients had clinical and radiological signs suggestive of the diagnosis, which were followed by an adequate response to antitubercular therapy.

According to the clinical presentation, fine needle aspiration or excision biopsy was performed in order to obtain a specimen for histological and microbiological (Ziehl-Neelsen staining) examination.

We haven't obtained ethical approval because of the noninterventional design of the study. Written informed consent was obtained from all patients.

\section{Statistical analysis}

Statistical analysis was performed using SPSS, version 20 (IBM Inc., Armonk, NY, USA). Categorical variables were expressed as numbers and percentages. Continuous variables were presented as means and standard deviations, if they were normally distributed. Median and interquartile ranges were used for non-normally distributed data.

\section{Results}

\section{Patient characteristics}

During the study period, 22 patients were confirmed to have breast TB. All patients were females. The mean age was $39 \pm 12$ years. Twelve patients were aged between 20 and 40 years. (54.6\%) and 11 patients were from rural areas (50\%). Three patients had a previous medical history of treated TB (13.6\%). One patient had a family history of pulmonary TB $(4.5 \%)$. At the time of diagnosis, five patients were pregnant $(22.7 \%)$, and three patients were lactating (13.6\%). In total, 18 patients were multiparous (81.8\%) and four patients were nulliparous (18.2\%) (Table 1).

Both lump and mastalgia were the presenting symptoms in 19 cases (86.3\%). Ipsilateral axillary lymphadenopathy was noted in 14 cases (63.6\%) and breast abscess in 11 cases (50\%). Laterality was reported as unilateral in 21 cases (95.5\%) and bilateral in one case (4.5\%). The mean size of the lump was $5.1 \pm 2.8 \mathrm{~cm}$. The lumps were located in the upper outer quadrant of the breast in 10 cases (45.5\%). Associated with breast TB, other foci of TB were noted in four cases (18.2\%), represented by cervical lymph node TB in all four (Table 1).
The median delay in seeking medical care was 40 (27-75) days. Elevated C-reactive protein level was noted in 10 cases (45.5\%) with a median level of 42 (25-53) mg/L. An accelerated erythrocyte sedimentation rate was noted in seven cases (31.8\%). Tuberculin skin test was positive in 13 cases (59.1\%). All patients tested negative for human immunodeficiency virus.

\section{Imaging features}

Ultrasound was performed in all cases. The most common finding was a well or poorly defined mass lesion, noted in

Table 1. Characteristics of patients with breast tuberculosis

\begin{tabular}{|c|c|c|}
\hline Variables & Number & Frequency (\%) \\
\hline \multicolumn{3}{|l|}{ Age categories (years) } \\
\hline $20-40$ & 12 & 54.6 \\
\hline $41-60$ & 8 & 36.4 \\
\hline$>60$ & 2 & 9 \\
\hline \multicolumn{3}{|l|}{ Clinical symptoms } \\
\hline Lump & 19 & 86.3 \\
\hline Mastalgia & 19 & 86.3 \\
\hline Ipsilateral axillary lymphadenopathy & 14 & 63.6 \\
\hline Breast abscess & 11 & 50 \\
\hline Breast fistula & 7 & 31.8 \\
\hline Nipple discharge & 5 & 22.7 \\
\hline Fever & 8 & 36.4 \\
\hline Weight loss & 3 & 13.6 \\
\hline Disseminated lesion & 2 & 9 \\
\hline Skin ulceration & 1 & 4.5 \\
\hline \multicolumn{3}{|l|}{ Location } \\
\hline Right side & 11 & 50 \\
\hline Left side & 10 & 45.5 \\
\hline Bilateral & 1 & 4.5 \\
\hline \multicolumn{3}{|l|}{ Asocciated site } \\
\hline Lymph node & 4 & 18.2 \\
\hline Pulmonary & 2 & 9 \\
\hline Neuromeningeal & 1 & 4.5 \\
\hline \multicolumn{3}{|l|}{ Diagnosis confirmation } \\
\hline $\begin{array}{l}\text { Histopathological proof: Epithelioid } \\
\text { cell granulomas and caseous } \\
\text { necrosis }\end{array}$ & 13 & 59.1 \\
\hline $\begin{array}{l}\text { Bacteriological proof: detection of } \\
\text { Mycobacterium tuberculosis* }\end{array}$ & 4 & 18.2 \\
\hline Clinically confirmed & 5 & 22.7 \\
\hline \multicolumn{3}{|l|}{ Disease evolution } \\
\hline Favorable & 20 & 91 \\
\hline Relapse & 2 & 9 \\
\hline
\end{tabular}


17 cases $(77.2 \%)$. Fistulous tracts were noted in seven cases (31.8\%), and ductal dilatation with echogenic component in six cases (27.2\%). The disseminated form was noted in two cases (9\%) with multiple collections mostly containing debris.

Mammography, performed in 19 cases (86.3\%), showed focal, asymmetric breast density in 17 cases (89.5\%) and diffuse in two cases (10.5\%) (Figure 1). Skin thickening was noted in five cases (26.3\%), multiple mass lesions in two cases $(10.5 \%)$ and microcalcifications without suspect grouping in three cases (15.7\%).

Magnetic resonance imaging was performed in three cases (13.6\%). One patient presented with a bilobed mass enhancement with intermediate intense T2, surrounded by a hypointense, regular and fine halo on T1, and an early and heterogenous enhancement (curve type 2). Multiple, confluent mass-enhancement with irregular margins was noted in one case. One of these masses presented as a rim enhancement pattern (Figure 2). Non-mass enhancement was noted in one case.

\section{Intervention and therapeutic procedure}

Excision biopsy was performed in seven cases (31.8\%). In order to exclude a possible breast cancer, lumpectomy was indicated in 10 cases $(45.5 \%)$ and mastectomy in two cases $(9 \%)$. The co-existence of breast TB and breast cancer was diagnosed in one patient, requiring mastectomy. The lack of response to antitubercular therapy associated with lesions involving the

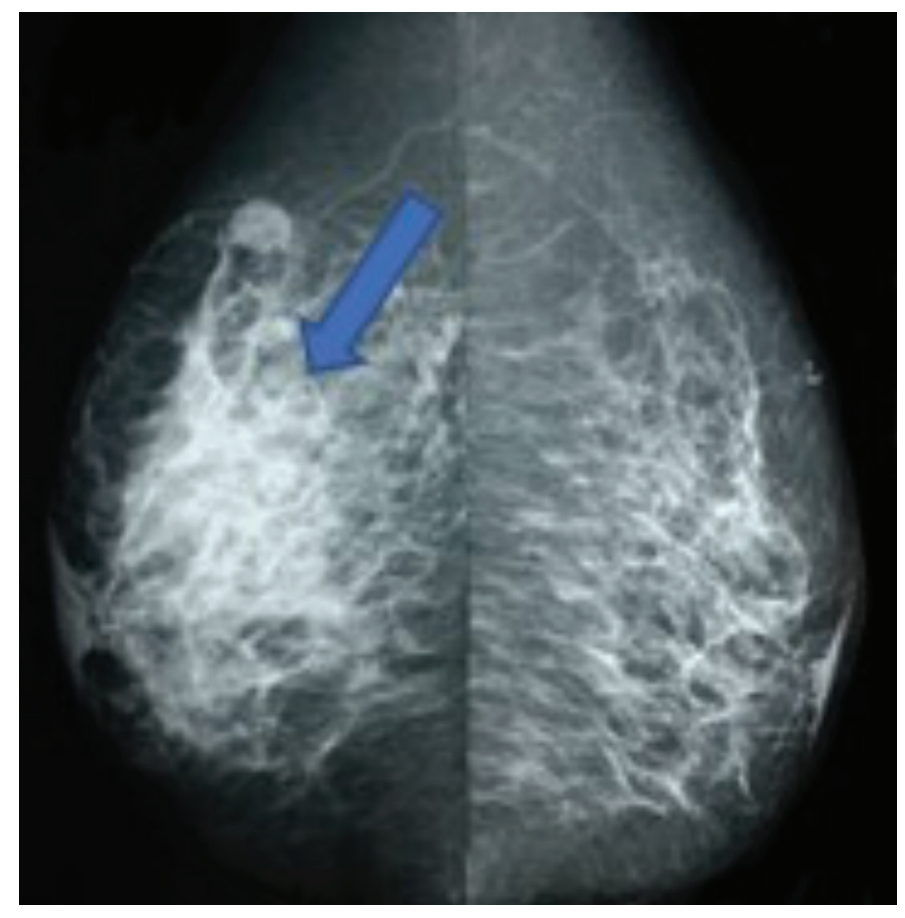

Figure 1. Standard craniocaudal view of the right and left breast shows an asymmetric density in the upper quadrant of the right breast (arrow) entire breast was the second indication for mastectomy in another patient. Drainage of the abscess was indicated in one case $(4.5 \%)$.

The diagnosis was confirmed based on the presence of epithelioid cell granulomas and caseous necrosis in 13 cases (59.1\%). The presence of epithelioid cell granulomas without caseous necrosis was noted in seven cases (31.8\%). The detection of Mycobacterium tuberculosis in smear or culture confirmed the diagnosis in four cases (18.2\%) (Table 1).

Patients received antitubercular therapy for a mean duration of $11 \pm 5$ months. Side effects of antitubercular therapy were noted in 10 cases (45.5\%), represented by the occurrence of gastrointestinal symptoms in 5 cases $(22.7 \%)$, the increase in hepatic enzyme levels (alanine aminotransferase and aspartate aminotransferase) in 3 cases (13.6\%) and skin reactions in 2 cases (9\%). The disease evolution was favorable in 20 cases (91\%). There were two relapsing cases (9\%). The median length of hospital stay was 7 (4-13) days.

\section{Discussion}

The diagnosis of breast TB cannot only rely on imaging results, which may be non-specific. A high index of suspicion followed by clinical and radiological examination and appropriate

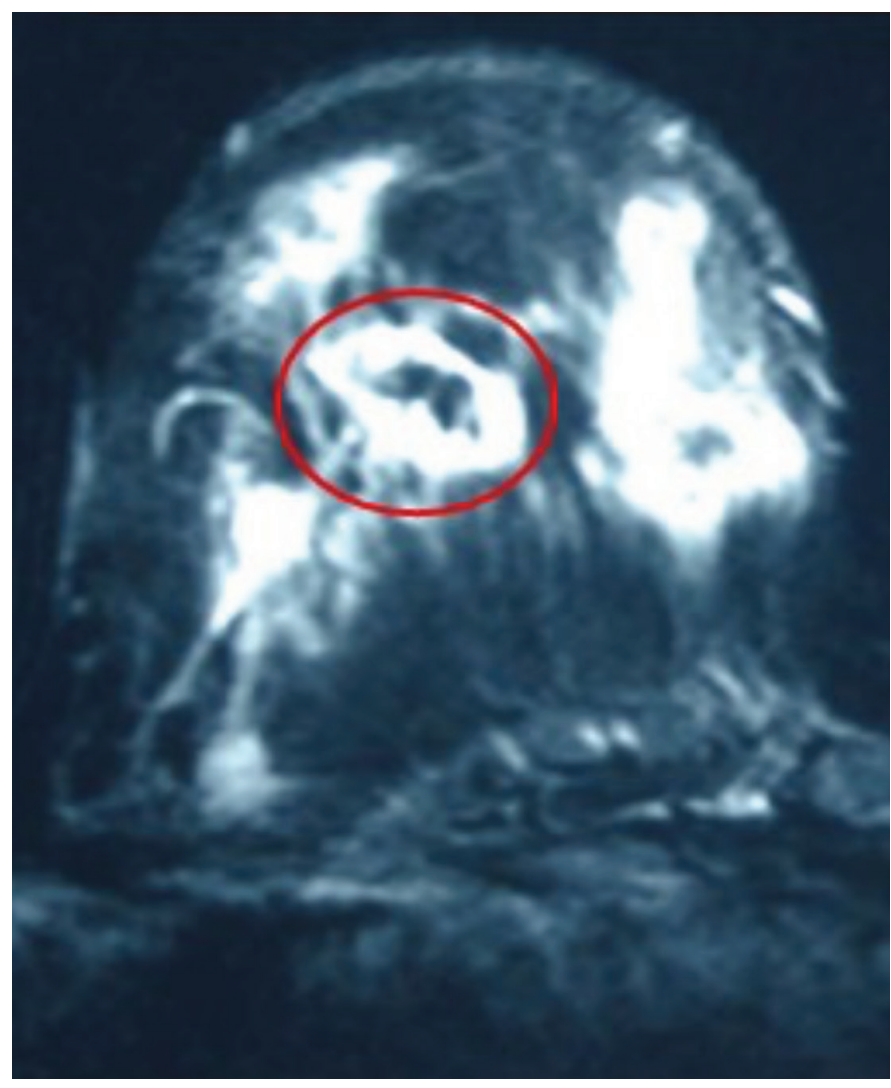

Figure 2. Breast magnetic resonance imaging shows multiple mass enhancement and a mass (encircled) with a rim enhancement 
biopsies are mandatory in order to confirm the diagnosis of breast TB. It remains a rare disease affecting commonly young, multiparous and lactating women (9). Its rarity is explained by the resistance of breast tissue to the infection, therefore inhibiting the survival and multiplication of Mycobacterium tuberculosis (10). However, during lactation, the breast is highly vascularized, and the ducts are dilated which explains the susceptibility to TB infection (11). A previous study, including 65 cases of breast $\mathrm{TB}$, reported a rate of $10.6 \%$ of lactating patients (8), which was similar to our results.

Breast TB was initially classified as primary when no other focus of TB was detectable, and secondary when it was associated with another focus of TB elsewhere in the body (12). Later, it was reported that breast TB is usually secondary, even if no other focus of TB was clinically or radiologically evident (13). We found other sites of TB associated with breast TB in 18.1\% of the cases, while a previous study reported a rate of $67.9 \%$, which was mostly represented by pleural and pulmonary TB (14). This discordance might be explained by the misdiagnosis of other sites of TB in our study.

In fact, secondary breast TB is commonly due to retrograde lymphatic spread from axillary lymph nodes, less commonly from cervical or mediastinal lymph nodes (15), which explains the frequent ipsilateral axillary lymphadenopathy associated with breast TB. Other sources of infection were reported, including hematogenous, or contiguous spread from the pleura or the chest wall (16).

Three types of breast TB have been reported, based on the clinical, radiological and pathological aspect of the disease. The nodular type is the most common, followed by the disseminated and the sclerosing form (17). Previous studies reported that the elderly present commonly with the nodular form, which mimics breast carcinoma clinically and radiologically $(18,19)$, while younger patients usually present with pyogenic abscess $(19,20)$.

Imaging features confirm the presence of the three forms of the disease, found during the clinical examination. The nodular form presents on mammography as an ill-defined density, which mimic breast cancer (21). The disseminated form is characterized by sinus formation secondary to multiple foci of TB (22). The irregularity of its margin might represent the tunneling of the abscesses and the associated blurring of the fat due to inflammatory reaction and edema (23), which mimic inflammatory carcinoma (15). The sclerosing form is seen when there is extensive fibrosis rather than caseation, and the entire breast hardens with a retracted nipple (4). Strong evidence of a tuberculous abscess is rarely found on mammography, which is represented by a dense sinus tract connecting an ill-defined breast mass to a localized skin thickening (24).
Imaging findings are of great interest in defining the extent of the lesion. However, distinguishing breast TB from breast cancer usually remains difficult (25). The simultaneous occurrence of breast cancer and TB has rarely been reported, and this diagnosis helps in down staging of carcinoma of breast and further management of the case (26). An excision biopsy, obtaining adequate tissue samples, is strongly recommended, which is not usually the case with fine needle aspiration (17). Demonstration of bacilli by microbiological, cytopathological or histopathological methods confirm the diagnosis of breast TB (2). This disease can present a diagnostic problem on radiological and microbiological investigations, and thus a high index of suspicion is needed.

The cornerstone of treatment remains antitubercular therapy prescribed for a minimum of six month (11). In order to prevent recurrence (27), or when the clinical response is slow (24), a prolonged treatment duration has been reported, as was the case with our patients. In fact, the associated site of TB may also interfere in the treatment duration, such as patient who presented with tuberculous meningitis. Along with medical therapy, surgical intervention might be required, if there is a lack of response to antitubercular therapy or due to the presence of lesions involving the entire breast (17). Another indication of mastectomy is the co-existence of breast TB and breast cancer, like the case of one of our patients. In fact, previous studies reported that radical mastectomy is indicated in the presence of clinically operable lesion, followed by antitubercular treatment, otherwise, palliative therapy combined with antitubercular treatment is indicated (28).

\section{Conclusion}

In our country, breast TB remains a rare and overlooked disease. The disease should be considered when young patients present with a palpable lump with axillary lymphadenopathy, especially in endemic regions. Although, imaging results were non-specific, they might aid in guiding clinicians. However, confirmation of a diagnosis of TB usually requires an excision biopsy providing histological or bacteriological evidence of infection.

Ethics Committee Approval: We haven't obtained ethical approval because of the non-interventional design of the study.

Informed Consent: Written informed consent was obtained from all patients.

Peer-review: Externally peer-reviewed.

Author Contributions: Surgical and Medical Practices: F.H., M.K., Y.H.; Concept: F.H., M.K., K.R., C.M., Z.M., M.B.J.; Design: 
F.H., M.K., A.C., M.B.J.; Data Collection or Processing: F.H., M.K., F.S., M.B.J.; Analysis or Interpretation: F.H., M.K., Y.H., C.M., M.B.J.; Literature Search: F.H., M.K., A.C., F.S., M.B.J.; Writing: F.H., M.K., M.B.J.

Conflict of Interest: No conflict of interest is declared by the authors.

Financial Disclosure: The authors declared that this study received no financial support.

\section{References}

1. World Health Organization. Global Tuberculosis Report 2019. Accessed on 7 June 2020.

2. Sinha R, Rahul. Breast tuberculosis. Indian J Tuberc 2019; 66: 6-11.

3. Green M, Millar E, Merai H, O'Shea M, Dedicoat M, Ingle H. Mammary tuberculosis in the young: a case report and literature review. Breast Dis 2012; 34: 39-42.

4. Thimmappa D, Mallikarjuna MN, Vijayakumar A. Breast Tuberculosis. Indian J Surg 2015; 77(Suppl 3): 1378-84.

5. Perrone C, Altieri AM, D'Antonio S, Leonetti C, Alma MG. Breast Tuberculosis after Chest Trauma - a Case Report and Review of the Literature. Breast Care (Basel) 2016; 11: 200-3.

6. Singal R, Bala J, Gupta S, Goyal S, Mahajan N, Chawla A. Primary breast tuberculosis presenting as a lump: a rare modern disease. Ann Med Health Sci Res 2013; 3: 110-2.

7. Primary Health care directory, Ministry of Health. Tuberculosis management guide in Tunisia 2018. Accessed on 9 June 2020. Available from: http://www.santetunisie.rns.tn/images/docs/anis/ actualite/2018/octobre/30102018Guide-PNLT-2018.pdf

8. Ben Hassouna J, Gamoudi A, Bouzaiene H, Dhiab T, Khomsi F, Chargui R, et al. Mammary tuberculosis: a retrospective study of 65 cases. Gynecol Obstet Fertil 2005; 33: 870-6.

9. Agarwal MD, Venkataraman S, Slanetz PJ. Uncommon Infections in the Breast. Semin Roentgenol 2017; 52: 108-13.

10. da Silva BB, Lopes-Costa PV, Pires CG, Pereira-Filho JD, dos Santos AR. Tuberculosis of the breast: analysis of 20 cases and a literature review. Trans R Soc Trop Med Hyg 2009; 103: 559-63.

11. Quaglio G, Pizzol D, Isaakidis P, Bortolani A, Tognon F, Marotta C, et al. Breast Tuberculosis in Women: A Systematic Review. Am J Trop Med Hyg 2019; 101: 12-21.
12. Tanrikulu AC, Abakay A, Abakay O, Kapan M. Breast Tuberculosis in Southeast Turkey: Report of 27 Cases. Breast Care (Basel) 2010; 5: 154-7.

13. Chandanwale S, Naragude P, Shetty A, Sawadkar M, Raj A, Bhide A, et al. Cytomorphological Spectrum of Granulomatous Mastitis: A Study of 33 Cases. Eur J Breast Heal 2020; 16: 146-51.

14. Darré T, Tchaou M, N'Timon B, Patassi AA, Aboubakari A, Sonhaye $\mathrm{L}$, et al. Tuberculosis of the Breast in Togo: A Series of 28 Presumed Cases. Bull Soc Pathol Exot 2017; 110: 238-41.

15. Sabaté JM, Clotet M, Gómez A, De Las Heras P, Torrubia S, Salinas T. Radiologic evaluation of uncommon inflammatory and reactive breast disorders. Radiographics 2005; 25: 411-24.

16. Kim HS, Cha ES, Kim HH, Yoo JY. Spectrum of sonographic findings in superficial breast masses. J Ultrasound Med 2005; 24: 663-80.

17. Baharoon S. Tuberculosis of the breast. Ann Thorac Med 2008; 3 : 110-4.

18. da Silva BB, Dos Santos LG, Costa PV, Pires CG, Borges AS. Primary tuberculosis of the breast mimicking carcinoma. Am J Trop Med Hyg 2005; 73: 975-6.

19. Kalaç N, Ozkan B, Bayiz H, Dursun AB, Demirağ F. Breast tuberculosis. Breast 2002; 11: 346-9.

20. O'Reilly M, Patel KR, Cummins R. Tuberculosis of the breast presenting as carcinoma. Mil Med 2000; 165: 800-2.

21. Stears L, Ismail F, Holl J. Primary tuberculosis of the breast: a rare cause of a breast lump. Breast Dis 2011; 33: 133-7.

22. Madhusudhan KS, Gamanagatti S. Primary breast tuberculosis masquerading as carcinoma. Singapore Med J 2008; 49: e3-5.

23. Sakr AA, Fawzy RK, Fadaly G, Baky MA. Mammographic and sonographic features of tuberculous mastitis. Eur J Radiol 2004; 51 : 54-60.

24. Khanna R, Prasanna GV, Gupta P, Kumar M, Khanna S, Khanna AK. Mammary tuberculosis: report on 52 cases. Postgrad Med J 2002; 78: 422-4.

25. Al-Marri MR, Aref E, Omar AJ. Mammographic features of isolated tuberculous mastitis. Saudi Med J 2005; 26: 646-50.

26. Jagtap SV, Naniwadekar RG, Jokhi CD, Jagtap SS. Invasive Breast Carcinoma with Axillary Tuberculous Lymphadenitis. J Clin Diagnostic Res 2018; 12: 1-3.

27. Al-Marri MR, Almosleh A, Almoslmani Y. Primary tuberculosis of the breast in Qatar: ten year experience and review of the literature. Eur J Surg 2000; 166: 687-90.

28. Farrokh D, Marashi M, Fallah Rastegar Y, Boloursaz Mashhadi S. The Coexistence of Carcinoma and Tuberculosis in One Breast: A Case Report and Literature Review. Int J Cancer Manag 2017; 10: e6185. 